\title{
Competitive and noncompetitive N-methyl-D-aspartate (NMDA) antagonists, haloperidol, and scopolamine impair performance in a nonspatial operant discrimination task
}

\author{
DAVID B. CLISSOLD, JOHN W. FERKANY, and MICHAEL J. PONTECORVO \\ Nova Pharmaceutical Corporation, Baltimore, Maryland
}

\begin{abstract}
The actions of competitive (NPC 12626 and CPP) and noncompetitive (PCP and MK 801) N-methylD-aspartate (NMDA) antagonists on performance of a nonspatial, operant repeated discrimination task were examined. The effects of the reference agents scopolamine and haloperidol were also examined. The competitive NMDA antagonist CPP, the noncompetitive NMDA antagonist MK 801 , and scopolamine increased the number of responses necessary to attain discrimination criterion. Only MK 801 simultaneously reduced the probability of a response during a trial and increased the probability of an intertrial interval response. Haloperidol reduced the number of sessions with a reliable number of responses but did not alter the total number of responses to criterion. The results suggest that both competitive and noncompetitive NMDA antagonists can disrupt cognitive processes that are involved in a variety of learning tasks, including nonspatial discrimination.
\end{abstract}

Excitatory amino acids (EAA) represent a major class of neurotransmitters in mammalian brain. Both ionotropic and metabotropic receptors for EAAs have been identified (Monaghan, Bridges, \& Cotman, 1989). The former, categorized by agonist profile, are referred to as kainic-acid-, quisqualic-acid-, or N-methyl-D-aspartic-acid(NMDA)preferring receptors (Watkins \& Evans, 1981).

Because of the availability of prototypical antagonists, the NMDA site has been most thoroughly studied. Present understanding suggests that the receptor may modulate a voltage-dependent ion channel through a supramolecular complex consisting of an agonist recognition site, an associated ionophore, and a cotransmitter or modulatory site activated in a strychnine-insensitive manner by the amino acid glycine. Other regulatory sites may also be associated with the complex (Bonhaus, Burge, \& McNamara, 1987; Coan \& Collingridge, 1987; Monaghan et al., 1989; Nowak, Bregestovsky, Ascher, Herbert, \& Prochiantz, 1984; Ransom \& Stec, 1988; Williams et al., 1988). Evaluation of both agonist and antagonist effects suggest that NMDA-receptor-mediated events may play a role in epilepsy, anxiety, acute and chronic neurodegeneration, nociception, and psychosis (Bennett \& Americk, 1986; Choi, 1988; Clark \& Rothman, 1987; Ferkany et al., 1989; Gilbert, 1988; Goldberg, Weiss, Pham, \& Choi, 1987; Raigorodsky \& Urca, 1987; Sato, Morimoto, \& Okamoto, 1988; Simon, Swan, Griffiths, \& Meldrum, 1984). Given

Correspondence should be addressed to David B. Clissold, Nova Pharmaceutical Corporation, 6200 Freeport Centre, Baltimore, MD 21224. this breadth of function, significant effort has been devoted to developing antagonists of the NMDA receptor. Competitive antagonists, including CPP [3-(2-carboxypiperizin-4-yl)propyl-1-phosphonic acid], NPC 12626 [2amino-4,5-(1,2-cyclohexyl)-7-phosphonoheptanoic acid], and CGS 19755 (cis-4-phosphono-methyl-2-piperidinecarboxylic acid), and noncompetitive antagonists or channel-blocking agents, such as MK 801 [(+)5-methyl10,11-dihydro-5H-dibenzo(a,d)-cyclohepten-5, 10-imine], have been proposed as clinical candidates.

Although offering a promising opportunity to treat CNS disorders, several lines of evidence indicate that the utility of NMDA antagonists as therapeutic agents may be limited by their side-effect profile. Effects on learning and other cognitive processes are of particular concern, since many of the proposed therapeutic applications require either chronic administration or administration to a cognitively compromised patient population, and since the noncompetitive NMDA antagonist phencyclidine (PCP; Jones, Snell, \& Johnson, 1987; Kemp, Foster, \& Wong, 1987) produces psychotomimetic and cognition-impairing effects (Burns \& Lerner, 1976; Henderson, 1982). In addition, evaluation of the effects of NMDA antagonists in animal models of learning and memory has led to converging lines of evidence suggesting a critical role for NMDA-mediated neurotransmission in the events underlying learning and synaptic plasticity. Pretreatment with NMDA antagonists is known to block the induction of LTP, but to have no effect if they are administered after the formation of LTP (Muller, Joly, \& Lynch, 1988). If, as hypothesized, similar mechanisms underlie both the 
LTP phenomenon and learning, NMDA antagonists that disrupt LTP should impair learning but not retrieval of well-learned information. Consistent with this hypothesis, it has been shown that NMDA antagonists impair acquisition (place learning) in water mazes, radial arm mazes, or passive avoidance but may not impair performance if they are administered after training (Butelman, 1990; DeNoble, Jones, Schaeffer, \& Bauerle, 1989; Morris, 1989; Morris, Anderson, Lynch, \& Baudry, 1986; Shapiro \& Caramanos, 1990; Venable \& Kelly, 1990; Wishaw \& Auer, 1989). It is important to note that all of these previous studies have employed tasks that require the subject to use spatial information to determine the location of a reward or escape. In fact, some investigators have argued that the effects of NMDA antagonists are selective for spatial (place) versus nonspatial (cued) acquisition tasks (Morris, 1989; Morris et al., 1986; Shapiro \& Caramanos, 1990).

The above results clearly demonstrate that NMDA antagonists disrupt performance in spatial tasks. The purpose of the present study was to explore the generality of cognitive impairment by testing competitive and noncompetitive NMDA antagonists in a nonspatial, operant acquisition task. The present task requires an association between a specific discriminative stimulus and an unambiguous response. In contrast to maze problems, spatial cues cannot be used to solve the discrimination problem. The present task is also a repeated measures procedure. Any effects of compounds are assessed against each rat's own control acquisition baseline.

The noncompetitive antagonists MK 801 and PCP and the competitive antagonists CPP and NPC 12626 were tested. This represents one of the first investigations into the effects of NPC 12626 on learning and memory performance (Pontecorvo, Clissold, White, \& Ferkany, 1991; Walker \& Gold, 1991). Scopolamine, a muscarinic antagonist known to interfere with both acquisition and recall in a number of tests, including spatial (Watts, Stevens, \& Robinson, 1981) and nonspatial problems (Pontecorvo et al., 1991), and haloperidol, a commonly prescribed antipsychotic thought to impair performance but not timedependent memory processes (Bartus, 1978; Poling, Picker, \& Thomas, 1984), were included for comparison.

\section{METHOD}

\section{Animals}

Thirteen male Sprague-Dawley rats (Harlan, Indianapolis, IN), 90-100 days old at the beginning of training, were housed singly in a temperature-controlled environment with a 12:12-h light:dark cycle. Subjective night began at $1030 \mathrm{~h}$, and testing was performed between 1200 and $1400 \mathrm{~h}$. The animals were allowed free access to Purina Rat Chow; however, access to water was restricted to a 40 -min period following the termination of each session.

\section{Apparatus}

Standard operant chambers (Model E10-10, Coulbourn Instruments, Lehigh Valley, PA) contained a water dispenser, a cue light (GE 1819), and a Sonalert tone source (Mallory SCG28F, $2500 \mathrm{~Hz}$ at $70 \mathrm{~dB}$ ) centered between two levers. Visual stimuli consisted of either a bright light or a dim light, with the bright light approximately 20 times brighter than the dim light. Auditory stimuli consisted of either the tone or a relay clicker (Newark BU24) programmed to close 20 times/sec. Each chamber was enclosed in a sound-attenuating shell, and white noise was presented continuously in the test room to further mask external noise. The apparatus was controlled by a PDP11/73 computer with a SKED interface (State Systems Inc., Kalamazoo, MI).

\section{Training}

The rats were shaped on successive days to press one, then the opposite, lever and then were trained in the repeated discrimination task. Each discrimination problem consisted of two of the four stimuli (bright light, dim light, tone, or clicker) designated S1 and $\$ 2$. Responses to the right-hand lever were reinforced in the presence of $S 1$, whereas responses on the left-hand lever were reinforced in the presence of $\mathbf{S 2}$. Stimuli (trials) were presented for $5 \mathrm{sec}$ or until a correct response was made. A 5-sec intertrial interval (ITI), which included a 1-sec pretrial delay (PTD), followed each stimulus presentation. Correction trials followed an incorrect response or response failure. Sessions were terminated in one of three ways: (1) after $60 \mathrm{~min}$, (2) following 400 trials, or (3) when discrimination criterion was met. Discrimination criterion was defined as at least 8 correct responses during the last 10 initial (noncorrection) trials for each stimulus. The rats were tested to criterion on a given discrimination problem. A different problem was presented the following day.

Table 1 lists the different patterns of auditory/visual stimulus pairs that can occur in consecutive discrimination problems (Sessions A-1 and $\mathbf{A}$ ). Problems were classified as either dimension-constant or dimension-reversal, depending on whether the relationship between the stimulus modality and the response location remained constant

Table 1

Patterns of Auditory/Visual Stimulus Pairs that Can Occur in Consecutive Discrimination Problems

\begin{tabular}{|c|c|c|c|c|c|}
\hline \multicolumn{6}{|c|}{ Session A-1 } \\
\hline & & Left Lever & \multicolumn{2}{|c|}{ Right Lever } & \\
\hline & & Bright light & \multicolumn{2}{|l|}{ Tone } & \\
\hline \multicolumn{6}{|c|}{ Session A } \\
\hline \multicolumn{3}{|c|}{ Dimension-Constant } & \multicolumn{3}{|c|}{ Dimension-Reversal } \\
\hline $\begin{array}{c}\text { Problem } \\
\text { Type }\end{array}$ & Left Lever & Right Lever & $\begin{array}{c}\text { Problem } \\
\text { Type }\end{array}$ & Left Lever & Right Lever \\
\hline $\mathrm{Cl}$ & $\begin{array}{l}\text { Dim light } \\
\text { Bright light }\end{array}$ & $\begin{array}{l}\text { Tone } \\
\text { Clicker }\end{array}$ & R1 & $\begin{array}{l}\text { Tone } \\
\text { Clicker }\end{array}$ & $\begin{array}{l}\text { Dim light } \\
\text { Bright light }\end{array}$ \\
\hline $\mathrm{C} 2$ & Dim light & Clicker & $\mathbf{R} 2$ & Clicker & Dim light \\
\hline
\end{tabular}


(e.g., bright light-left lever/tone-right lever followed by dim lightleft lever/clicker-right lever) or varied (e.g., to clicker-left lever/dim light-right lever) relative to the previous problem. Dimension-constant problems could introduce one (C1) or two (C2) "novel" stimuli (relative to Session A-1), and a similar pattern could be obtained for dimension-reversal problems (R1, R2), yielding four auditory/visual problem types. Not shown in Table 1 are the withindimension discriminations. It was apparent during training that visual or auditory discriminations (bright vs. dim light or tone vs. clicker) were less reliably acquired within a session than problems that utilized dimension as a relevant cue. Therefore, drug test sessions were restricted to problem types $C 1, C 2, R 1$, and $R 2$, all of which included one visual and one auditory stimulus.

Prior to the start of compound testing, the rats were exposed to a random sequence of problems for 60 sessions. Repeated measures analysis of variance (ANOVA) comparing the last four problems of each auditory/visual type revealed stable daily acquisition (responses to criterion) within each problem type. This was arbitrarily designated as baseline performance.

\section{Compound Testing}

The rats were divided into two groups, roughly matched for baseline accuracy. Testing continued 5 days per week with drug sessions on Tuesdays and Fridays. Group 1 rats were challenged with CPP ( 5 or $10 \mathrm{mg} / \mathrm{kg}$, Tocris Neuramin, Essex, UK), PCP (1 or $3 \mathrm{mg} / \mathrm{kg}$, Sigma, St. Louis, MO), haloperidol ( 0.075 or $0.1 \mathrm{mg} / \mathrm{kg}$, Research Biochemicals Inc., Natick, MA), or saline. Rats in Group 2 received NPC 12626 (15 or $25 \mathrm{mg} / \mathrm{kg}$, Nova Pharmaceutical Corp., Baltimore, MD), MK 801 maleate $(0.1$ or $0.2 \mathrm{mg} / \mathrm{kg}$, Research Biochemicals), scopolamine hydrobromide $(0.3 \mathrm{mg} / \mathbf{k g}$, Sigma), or saline. All drugs except haloperidol were freshly dissolved in saline and administered intraperitoneally in a volume of $1.0 \mathrm{ml} / \mathrm{kg} 30 \mathrm{~min}$ prior to the test session. Haloperidol was dissolved in glacial acetic acid $(10 \mu \mathrm{l})$ and brought to volume with distilled water ( $\mathrm{pH}=5-6$ ). The order of drug administration was alternated so that the rats were never administered the same agent twice during any 7-day period.

\section{Data Analysis}

The total number of choice/trial responses (a leverpress during any stimulus presentation) was recorded for each session. Total responses to criterion, rather than total trials to criterion, was used as the index of acquisition rate to minimize possible confounding by changes in response probability. The probability of a response was calculated by dividing the total number of responses (correct plus incorrect) by the total number of response opportunities (initial trials plus correction trials). ITI response probabilities were calculated by dividing all responses made during the ITIs (including those made during the PTD) by the total number of ITIs.

\section{RESULTS}

An ANOVA with dimension relationship ( $C$ or $R$ ), number of novel stimuli ( 1 or 2 ), and replications (first and last saline treatments) was used to compare the number of responses to criterion as a function of problem type and to evaluate the stability of control performance throughout the test phase. A main effect of dimension relationship $[F(1,12)=22.9]$ indicated that dimension-constant problems were acquired in fewer responses than were dimension-reversal problems. There was no significant effect of the number of novel stimuli or the interaction of this factor with the dimension factor. However, a dimension $\times$ replication interaction $[F(1,12)=19.4]$ suggested that criterion for dimension-reversal problems was achieved in fewer responses in the latter stages of the test phase. This impression was confirmed by separate ANOVAs for all dependent variables for constant and reversal problem types. Although there were no significant effects of stimulus number, replication, or interaction involving these factors for constant-dimension problems, a main effect of replication was obtained for reversal problems $[F(1,12)=40.9]$, indicating that criterion was achieved in fewer responses for both $R 1$ and $R 2$ problems by the end of the test phase. Because it is difficult to interpret drug effects given a changing baseline, only drug data obtained with constant-dimension problems received further consideration. Data from constant-dimension problems were combined over replications (regardless of the number of novel stimuli) in all subsequent repeated measures ANOVAs with drug dose as the within-subject factor. To assist in distinguishing between learning or performance effects of a compound, data were included only if the rat either responded on at least $50 \%$ of the trials or achieved criterion on that day. In the latter case, the data were included regardless of the overall probability of a response. If one dose replication satisfied one of these requirements but the other did not, only the session that met one of these conditions was used in the ANOVA. The effect of these restrictions was to disqualify from further analysis 1 rat from the $10-\mathrm{mg} / \mathrm{kg}$ CPP condition, 1 rat from the 0.3 $\mathrm{mg} / \mathrm{kg}$ scopolamine condition, 3 rats from the $0.075-\mathrm{mg} / \mathrm{kg}$ haloperidol condition, and 4 rats from the $0.1-\mathrm{mg} / \mathrm{kg}$ haloperidol condition.

Figure 1 illustrates the effects of the various compounds on the primary dependent variable, total responses to criterion. CPP $[F(2,10)=11.08, p=.003]$ and MK 801 $[F(2,10)=4.13, p=.049]$ significantly increased the number of responses necessary to achieve discrimination criterion. A subsequent ANOVA indicated that the effect was primarily due to the $10-\mathrm{mg} / \mathrm{kg} \operatorname{CPP}[F(1,5)=12.75$, $p=.016]$ and $0.2-\mathrm{mg} / \mathrm{kg} \mathrm{MK} 801[F(1,5)=15.35, p=$ $.011]$ doses. Scopolamine at $0.3 \mathrm{mg} / \mathrm{kg}$ also significantly increased the number of responses to criterion $[F(1,4)=$ $18.16, p=.013$ ]. NPC 12626, PCP, and haloperidol did not affect this measure at the doses tested.

Figure 2 illustrates the effects of the various compounds on the probability of a response and the percentage of sessions in which the response criterion (responses to more than $50 \%$ of trials) was met. Of the NMDA antagonists, only MK $801[F(2,10)=7.87, p=.030]$ significantly reduced the probability of a response to a given trial. A subsequent ANOVA indicated that this effect was mainly due to the $0.2-\mathrm{mg} / \mathrm{kg} \mathrm{MK} 801[F(1,5)=11.52, p=.019]$ dose. Haloperidol also appeared to reduce the probability of a response. On closer inspection, the responsesuppressant effects of $0.075 \mathrm{mg} / \mathrm{kg}$ of haloperidol appeared to be all or none, since either responding was greatly reduced $(75 \%$ or more initial trials without a response) or responding was not affected. Variance occurred both between subjects and within subjects during replication of the same dose. Since so few degrees of free- 

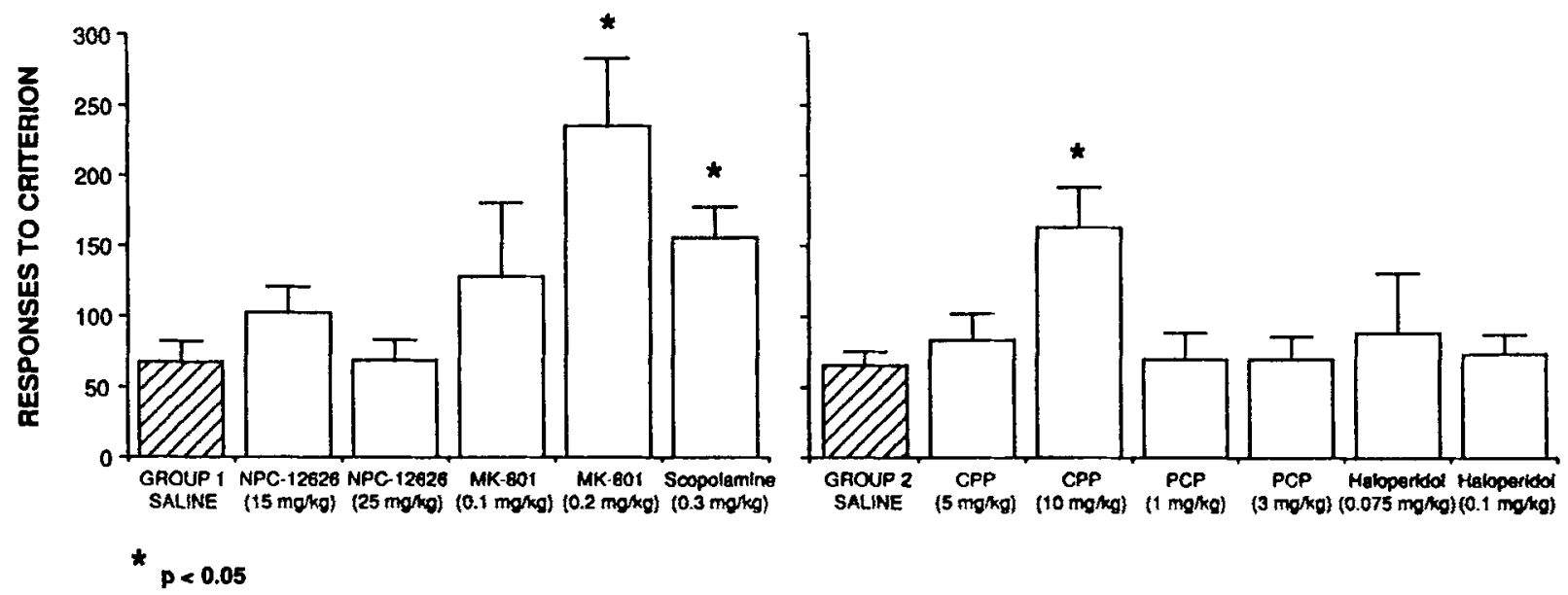

Figure 1. Mean (+1 SEM) responses to criterion under saline and drug conditions. Competitive (CPP, $10 \mathrm{mg} / \mathrm{kg})$ and noncompetitive (MK $801,0.2 \mathrm{mg} / \mathrm{kg})$ NMDA antagonists, as well as scopolamine $(0.3 \mathrm{mg} / \mathrm{kg})$, significantly increased the number of responses to criterion.
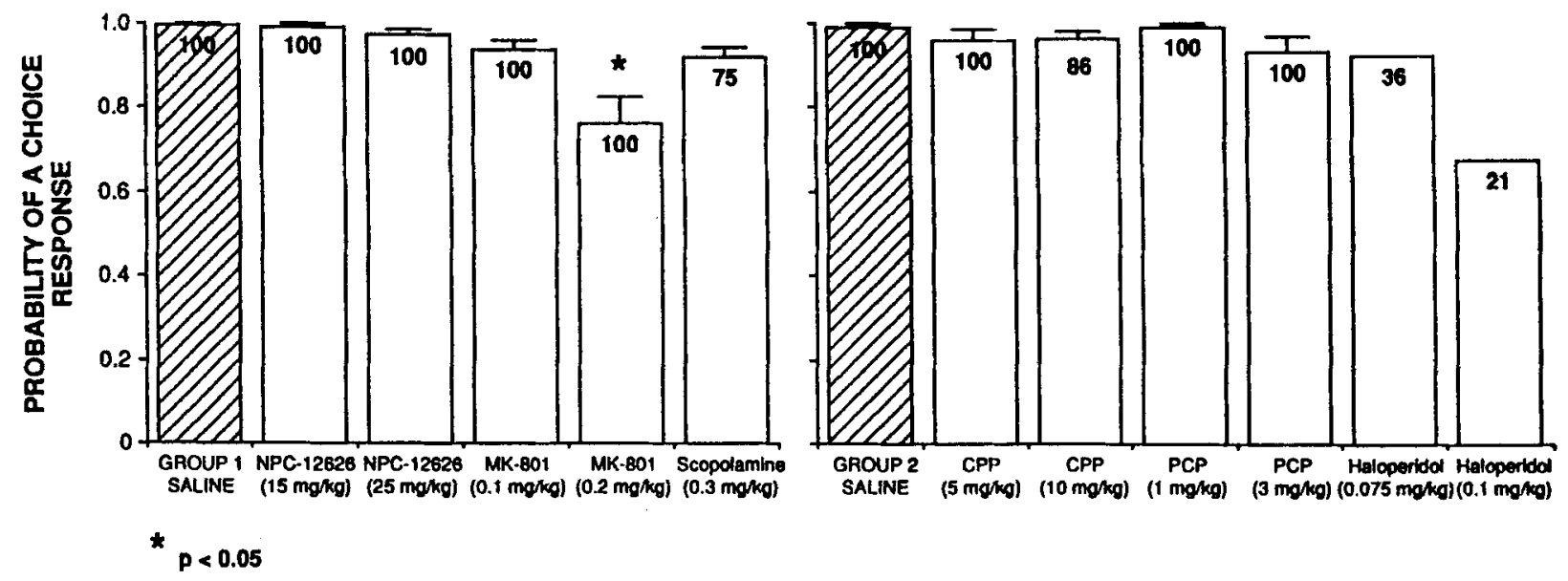

Figure 2. Probability of a choice response (bars) and percentage of test sessions with responses to more than $50 \%$ of trials (insets) under saline and drug conditions. Only MK $801(0.2 \mathrm{mg} / \mathrm{kg})$ significantly reduced the probability of a choice response to an initial stimulus.

dom remained, an ANOVA was not performed. Note in Figure 2 the marked reduction in the percentage of sessions meeting the response criterion following a haloperidol injection.

Scopolamine, CPP, PCP, and NPC 12626 did not significantly alter the probability of a choice response. Recall that 1 rat from the $10-\mathrm{mg} / \mathrm{kg}$ CPP condition $(26 \%)$ and 1 rat from the $0.3-\mathrm{mg} / \mathrm{kg}$ scopolamine condition (2\%) did not achieve the minimum $50 \%$ response criterion on either replication and were excluded from this ANOVA. However, post hoc ANOVAs that included these rats were also performed. In all cases, the reduction in response probability by either CPP or scopolamine was not significant.

Only MK 801 at $0.2 \mathrm{mg} / \mathrm{kg}$ significantly increased the probability of a response during the ITI $[F(1,5)=6.60$, $p=.050$ ]. Rats treated with this dose of MK 801 produced a response/ITI ratio greater than 0.75 , whereas the same rats produced a ratio of 0.30 following a saline in- jection. Note that this increased probability of an ITI response occurred along with an increased number of responses to criterion. Thus, the absolute number of ITI responses in a given session under MK 801 was far greater than the number of responses under control conditions.

\section{DISCUSSION}

The competitive NMDA antagonist CPP, the noncompetitive NMDA antagonist MK 801, and scopolamine disrupted acquisition in the present nonspatial repeated discrimination task. Although a number of investigators have found that NMDA antagonists impair acquisition in spatial tasks (Butelman, 1990; Danysz, Wroblewski, \& Costa, 1988; DeNoble et al., 1989; McCann \& Winter, 1986; Morris, 1989; Venable \& Kelly, 1990; Wishaw \& Auer, 1989; Wozniak, Olney, Kettinger, Price, \& Miller, 1990 ), the present results support the notion that at least 
some NMDA antagonists disrupt acquisition in nonspatial tasks as well (Robinson, Crooks, Shinkman, \& Gallagher, 1989; Tan, Kirk, Abraham, \& McNaughton, 1989). Only MK 801 simultaneously reduced the probability of a response during a trial and increased the probability of an ITI response. The competitive NMDA antagonist NPC 12626 and the noncompetitive NMDA antagonist PCP did not affect any measure at the doses tested. Haloperidol generally decreased the probability of a behavioral response without affecting choice accuracy.

That MK 801 but not PCP, and that CPP but not NPC 12626 , affected acquisition in the present task may reflect an inappropriate choice of doses for the ineffective compounds. For example, both competitive (CPP, $5 \mathrm{mg} / \mathrm{kg}$; NPC 12626, $40 \mathrm{mg} / \mathrm{kg}$ ) and noncompetitive (MK 801, $0.1 \mathrm{mg} / \mathrm{kg}$; PCP, $6.25 \mathrm{mg} / \mathrm{kg}$ ) NMDA antagonists impaired short-term or trial-unique memory in a nonspatial operant continuous nonmatch (CNM) procedure (Pontecorvo et al., 1991). Note that the doses of NPC 12626 and PCP necessary to produce a working-memory impairment were greater than the doses used in the present task. Since MK 801 and CPP impaired performance in both tasks at similar doses, it is possible that higher doses of PCP and NPC 12626 would be required to impair performance across these tasks.

The present results extend our earlier report that doses of noncompetitive antagonists, particularly MK 801, that decrease response accuracy also increase the probability of an inappropriate (ITI) response in the CNM task (Pontecorvo et al., 1991). This increase in ITI responding may reflect inattention, a general disorientation, or a loss of control by the experimental stimuli or contingencies. However, we do not believe it to be an artifact or secondary to either a stimulant effect or sensorimotor impairment. It is difficult to attribute the increased ITI response probability to a general stimulant effect of MK 801, since response probability during a trial decreased in both experiments. MK 801, at sufficiently high doses, has been reported to produce a sensorimotor deficit that could reduce the ability to navigate a maze and thus confound interpretation of place acquisition experiments (Keith \& Rudy, 1990). In the present experiment, and in the previous CNM task, it was found not only that MK 801-treated rats were able to perform the barpress response, but that the probability of this response increased during the ITI. The fact that rats continued responding in both operant tasks suggests that sensorimotor impairment was not a significant factor.

Scopolamine also impaired acquisition in the present task. This result is consistent with hypotheses that assign a critical role to intact central cholinergic function in modulation of learning and memory (Carlton, 1969) and is consistent with the impairment produced by scopolamine in other learning and memory tasks (Dilts \& Berry, 1967; Glick \& Zimmerberg, 1972; Heise, Conner, \& Martin, 1976; Kirk, White, \& McNaughton, 1988; Ponte- corvo, et al., 1991; Watts et al., 1981), as well as with scopolamine-induced disruptions of acquisition and performance of a simple discrimination task (Spangler, Chachich, \& Ingram, 1988; Spencer, Pontecorvo, \& Heise, 1985). As has been reported for other tasks, scopolamine impaired choice accuracy in the present task, with little effect on other performance indices. Responding during incorrect intervals (the ITI) was not affected by scopolamine, nor was overall response probability reduced. Thus, the present results suggest that the differences in performance are probably not due to a change in motivation or attention.

That CPP and scopolamine produced similar impairments in the present task may reflect a common neural area of action or psychological process that is compromised by both classes of drug. Similarly, it is not clear if the effects of scopolamine, CPP, or MK 801 should be attributed to learning impairment exclusively or whether other abilities necessary to achieve criterion performance might also be compromised, including deficits in attention (Heise \& Milar, 1984), stimulus sensitivity (Warburton \& Brown, 1971), or discriminability (Milar, 1981). Without further investigation of variables such as class of compound (including higher doses of PCP and NPC 12626), stimulus salience, or memory load, such a conclusion is premature. Finally, although these results suggest that CPP, in contrast to MK 801, disrupts acquisition without producing shifts in response probability, additional research will be required to determine whether this reflects a more favorable side-effect profile or predicts a better therapeutic/toxic ratio for competitive NMDA antagonists in a clinical setting.

Haloperidol generally decreased responding, but this effect was not reliably reproducible either between or within subjects. In the present experiment, no effect on acquisition could be found in the few rats that responded to more than $50 \%$ of the trials. Other investigators have demonstrated that haloperidol disrupts performance in a delayed-response procedure in rhesus monkeys (Bartus, 1978) and in a delayed matching-to-sample task in pigeons (Poling et al., 1984). In both studies, the effects were dose but not delay dependent, suggesting a general disruption of behavior. As in the present experiment, the highest doses of haloperidol greatly reduced behavioral responding.

In conclusion, a competitive NMDA antagonist (CPP), a noncompetitive NMDA antagonist (MK 801), and scopolamine increased the number of responses necessary to achieve criterion performance. Thus, in addition to their well-documented effects in spatial tasks, at least some NMDA antagonists disrupt nonspatial acquisition. Only MK 801 reduced trial response probability and increased the probability of a response during an ITI. It is important to note that none of the NMDA antagonists impaired the rats' ability to perform the barpress response. Thus, any sensorimotor impairment caused by these compounds probably played an insignificant role in the results ob- 
tained. To more accurately define an experimentally induced cognitive impairment, nonspatial tests such as repeated discrimination may prove useful.

\section{REFERENCES}

BArTus, R. T. (1978). Short-term memory in the thesus monkey: Effects of dopamine blockade via acute haloperidol administration. Pharmacology, Biochemistry \& Behavior, 9, 353-357.

BENNETT, D. A., \& AMERICK, C. L. (1986). 2-amino-7-phosphonoheptanoic acid (AP7) produces discriminative stimuli and anticonflict effects similar to diazepam. Life Sciences, 39, 2455-2461.

Bonhaus, D. W., Burge, B. C., \& McNamara, J. O. (1987). Biochemical evidence that glycine allosterically regulates an NMDA receptorcoupled ion channel. Eunopean Joumal of Pharmacology, 142, 489-490.

Burns, R. S., Lerner, S. E. (1976). Perspective: Acute phencyclidine intoxication. Clinical Toxicology, 9, 477-501.

Butelman, E. R. (1990). The effects of NMDA antagonists in the radial arm maze task with an interposed delay. Pharmacology, Biochemistry \& Behavior, 35, 533-536.

CARLton, P. L. (1969). Brain acetylcholine and inhibition. In J. T. Tapp (Ed.), Reinforcement and behavior (pp. 286-327). New York: Academic Press.

CHOI, D. W. (1988). Calcium-mediated neurotoxicity: Relationship to specific channel types and role in ischemic damage. Trends in Neurosciences, 11, 465-469.

Clark, G. D., \& Rothman, S. M. (1987). Blockade of excitatory amino acid receptors protects anoxic hippocampal slices. Neuroscience, 21, 665-671.

ConN, E. J., \& Collingridge, G. L. (1987). Effects of phencyclidine, SKF 10,047 and related psychotomimetic agents on N-methyl-Daspartate receptor mediated synaptic responses in rat hippocampal slices. British Joumal of Pharmacology, 91, 547-556.

DANYsz, W., WroBlewsKu, J. T., \& CostA, E. (1988). Leaming impairment in rats by $\mathrm{N}$-methyl-D-aspartate antagonists. Neuropharmacology, 27, 653-656.

DeNoble, V. J., Jones, K. W., Schaeffer, C. L., Bauerle, L. M. (1989). CPP and PCP produce amnesia of a passive avoidance response in rats. Society for Neuroscience Abstracts, 15, 1166.

Dilts, S. L., Berry, C. A. (1967). Effects of cholinergic drugs on passive avoidance in the mouse. Joumal of Pharmacology \& Experimental Therapeutics, 158, 279-285.

Ferkany, J. W., KYle, D. K., Willets, J., Rzeszotarsk, W. J., Guzewska, M. E., Ellenberger, S. R., Jones, S. M., Sacann, A. I., SNell, L. D., Borosky, S., Jones, B. E., Johnson, K. M., Balster, R. L., BubChett, K., KaWASAki, K., Hoch, D. B., De DNGLEDINE, R. (1989). Pharmacological profile of NPC 12626, a novel, competitive N-methyl-D-aspartate receptor antagonist. Joumal of Pharmacology \& Experimental Therapeutics, 250, 100-109.

GILBERT, M. E. (1988). The NMDA-receptor antagonist, MK-801, suppresses limbic kindling and kindled seizures. Brain Research, 463, $90-99$.

GuCK, S. D., ZMMMerbero, B. (1972). Amnesic effects of scopolamine. Behavioral Biology, 7, 245-254.

Goldberg, M. P., Weiss, J. H., Pham, P. C., Choi, D. W. (1987). $\mathrm{N}$-methyl-D-aspartate receptors mediate hypoxic neuronal injury in cortical culture. Joumal of Pharmacology \& Experimental Therapeutics, 243, 784-791.

Heise, G. A., Conner, R., \&ARTin, R. A. (1976). Effects of scopolamine on variable intertrial interval spatial alternation and memory in the rat. Psychopharmacology, 49, 131-137.

Heise, G. A., Milar, K. S. (1984). Drugs and stimulus control. In L. L. Iversen, S. D. Iversen, \& S. H. Snyder (Eds.), Handbook of psychopharmacology (Vol. 18, pp. 129-190). New York: Plenum.

HENDERSON, G. (1982). Phencyclidine. A widely abused but little understood psychotomimetic agent. Trends in Phamacological Sciences, 5, 248-250.

Jones, S. M., Snell, L. D., \& Johnson, K. M. (1987). Phencyclidine selectively inhibits $\mathrm{N}$-methyl-D-aspartate-induced hippocampal $\left[{ }^{3} \mathrm{H}\right]$ norepinephrine release. Joumal of Pharmacology \& Experimental Therapeutics, 240, 492-497.

KeITH, J. R., RUDY, J. W. (1990). Why NMDA-receptor-dependent long-term potentiation may not be a mechanism of learning and memory: Reappraisal of the NMDA-receptor blockade strategy. Psychobiology, 18, 251-257.

Kemp, J. A., Foster, A. C., * Wong, E. H. F. (1987). Non-competitive antagonists of excitatory amino acid receptors. Trends in Neurasciences, 10, 294-298.

KIRK, R. C., WhITE, K. G., MCNaughton, N. (1988). Low dose scopolamine affects discriminability but not rate of forgetting in delgyed conditional discrimination. Psychopharmacology, 96, 541-546.

MCCANN, D. J., \& WINTER, J. C. (1986). Effects of phencyclidine, Nallyl-N-normetazocine (SKF-10,047), and verapamil on performance in a radial maze. Pharmacology, Biochemistry \& Behavior, 24, 187-191.

MilaR, K. S. (1981). Cholinergic drug effects on visual discriminations: A signal detection analysis. Psychopharmacology, 74, 383-388.

Monaghan, D. T., Bridges, R. J., Cotman, C. W. (1989). The excitatory amino acid receptors: Their classes, pharmacology, and distinct properties in the function of the central nervous system. Annual Review of Pharmacology \& Toxicology, 29, 365-402.

Morris, R. G. M. (1989). Synaptic plasticity and learning: Selective impairment of learning in rats and blockade of long-term potentiation in vivo by the $\mathrm{N}$-methyl-D-aspartate receptor antagonist AP5. Journal of Neuroscience, 9, 3040-3057.

Morris, R. G. M., Anderson, E., Lynch, G. S., \& BAudry, M. (1986). Selective impairment of learning and blockade of long-term potentiation by an $\mathrm{N}$-methyl-D-aspartate antagonist, AP5. Nature, 319, 774-776.

MulleR, D., Joly, M., LYNCH, G. (1988). Contributions of quisqualate and NMDA receptors to the induction and expression of LTP. Science, 242, 1694-1697.

Nowak, L., Bregrstovsky, P., Ascher, P., Herbert, A., a Prochinntz, A. (1984). Magnesium gates glutamate-activated channels in mouse central neurones. Nature, 307, 462-465.

Polng, A., Prcker, M., \& Thomas, J. (1984). Effects of chlorprothixene, haloperidol, and trifluoperazine on the delayed-matching-to-sample performance of pigeons. Pharmacology, Biochemistry \& Behavior, 21, 721-726.

Pontecorvo, M. J., Clissold, D. B., White, M. F., Ferkany, J. W. (1991). NMDA antagonism and working memory performance: Comparison to the effects of scopolamine, propranolol, diazepam, and phenylisopropyladenosine. Betzavional Neurascience, 105, 521-535.

RAIGORODSKY, G., URCA, G. (1987). Intrathecal N-methyl-D-aspartate (NMDA) activates both nocioeptive and antinocioeptive systems. Brain Research, 422, 158-162.

RAnsom, R. W., \& Stec, M. L. (1988). Cooperative modulation of [ $\left.{ }^{3} \mathrm{H}\right] \mathrm{MK}-801$ binding to the $\mathrm{N}$-methyl-D-aspartate receptor-ion channel complex by l-glutamate, glycine and polyamines. Joumal of Neurochemistry, 51, 830.

Robinson, G. S., Jr., Crooks, G. B., Jr., Shinkman, P. G., GalLAGHER, M. (1989). Behavioral effects of MK-801 mimic deficits associated with hippocampal damage. Psychobiology, 17, 156-164.

SAto, K., Morimoto, K., \& OKamoto, M. (1988). Anticonvulsant action of a non-competitive antagonist of NMDA receptors (MK-801) in the kindling model of epilepsy. Brain Research, 463, 12-20.

Shaptro, M. L., C Caramanos, Z. (1990). NMDA antagonist MK801 impairs acquisition but not performance of spatial working and reference memory. Psychobiology, 18, 231-243.

Simon, R. P., Swan, J. H., Griffiths, T., Meldrum, B. S. (1984). Blockade of $\mathrm{N}$-methyl-D-aspartate receptors may protect against ischemic damage in the brain. Science, 226, 850-852.

Spangler, E. L., Chachich, M. E., Ingram, D. K. (1988). Scopolamine in rats impairs acquisition but not retention in a 14-unit $\mathrm{T}$-maze. Pharmacology, Biochemistry \& Behavior, 30, 949-955.

Spencer, D. G., Pontecorvo, M. J., Heise, G. A. (1985). Central cholinergic involvement in working memory: Effects of scopolamine 
on continuous nonmatching and discrimination performance in the rat. Behavioral Neuroscience, 99, 1049-1065.

Tan, S., Kirk, R. C., Abraham, W. C., \& McNaughton, N. (1989). Effects of the NMDA antagonists CPP and MK-801 on delayed conditional discrimination. Psychopharmacology, 98, 556-560.

VeNABLE, N., KelLY, P. H. (1990). Effects of NMDA receptor antagonists on passive avoidance leaming and retrieval in rats and mice. Psychopharmacology, 100, 215-221.

WALKER, D. L., GoLD, P. E. (1991). Effects of the novel NMDA antagonist, NPC 12626, on long term potentiation, learning, and memory. Brain Research, 549, 213-221.

Warburton, D. M., \& Brown, K. (1971). Scopolamine-induced attenuation of stimulus sensitivity. Nature, 230, 126-127.

Watkins, J. C., Evans, R. H. (1981). Excitatory amino acid neurotransmitters. Annual Review of Pharmacology \& Toxicology, 21, 165-204.
Watts, J., Stevens, R., Robinson, C. (1981). Effects of scopolamine on radial maze performance in rats. Physiology \& Behavior, 26, 845-851.

Williams, M., Loo, P. A., Murphy, D. E., Braunwalder, A. F., JARvis, M. F., \& Sills, M. A. (1988). The N-methyl-D-aspartate receptor complex. Joumal of Receptor Research, 8, 195-203.

Wishiw, I. Q., AUER, R. N. (1989). Immediate and long-lasting effects of MK-801 on motor activity, spatial navigation in a swimming pool and EEG in the rat. Psychopharmacology, 98, 500-507.

Wozniak, D. F., Olney, J. W., Kettinger, L., Price, M., Miller, J. P. (1990). Behavioral effects of MK-801 in the rat. Psychopharmacology, 101, 47-56.

(Manuscript received February 14, 1991; revision accepted for publication July 25,1991 .)

\title{
Notice
}

\author{
Call for Assistance in \\ The Compilation of a History of the Psychonomic Society
}

The Governing Board of the Psychonomic Society is pleased to announce that Robert C. Bolles has agreed to serve as the first Historian of the Society.

All members who might have information relevant to this undertaking are invited to send it directly to Dr. Bolles. Founding members and those who attended the early meetings are especially encouraged to record their reminiscences. While Dr. Bolles hopes to collect as much information as possible relevant to the history of the Society, he will concentrate first on the early history.

Dr. Bolles's address is Department of Psychology, University of Washington, Seattle, Washington 98195 (phone: 206-543-2631). 